\title{
Biodeterioration of concrete in agricultural, agro-food and biogas plants: state of the art and challenges
}

\author{
Alexandra Bertron ${ }^{a^{*}}$, Matthieu Peyre Lavigne $^{\mathrm{b}}$, Cédric Patapy $^{\mathrm{a}}$, Benjamin Erable ${ }^{\mathrm{c}}$ \\ a LMDC, Université de Toulouse, INSA, UPS, 135 Avenue de Rangueil, 31077, Toulouse cedex , France \\ ${ }^{b}$ LISBP, Université de Toulouse, CNRS, INRA, INSA, 135 Avenue de Rangueil, 31077, Toulouse cedex 04, France \\ ' LGC, Université de Toulouse, CNRS, INPT, UPS, 4 Allée Emile Monso, 31432 Toulouse, France
}

Received: 28 November 2017 / Accepted: 28 December 2017 / Published online: 30 December 2017

(C) The Author(s) 2017. This article is published with open access and licensed under a Creative Commons Attribution 4.0 International License.

\begin{abstract}
This article reviews the state of knowledge on the mechanisms of deterioration of concrete by agricultural and agro-industrial effluents, notably breeding effluents and biowaste valorised in anaerobic digestion plants. The main physicochemical characteristics of agricultural effluents are first listed in terms of components that are aggressive for cementitious materials. Then, the main mechanisms of deterioration of the cementitious materials exposed to the effluents are presented, as highlighted by laboratory studies (synthetic effluents and / or models, specific experimental devices) or with real effluents. The paper also points out the scientific and technical advances needed to improve the durability of concrete in these environments.
\end{abstract}

Keywords: Cementitious materials; Biodeterioration; Agricultural effluents; Organic acid; Biofilm

\section{Introduction}

Concrete is widely used for the construction of agricultural and agro-food structures, such as barns, dairy plants, agrofood plants, plants for the production, collecting, storage and treatment of agricultural effluents, biogas digesters, etc. However, the aggressive nature of agricultural and agro-food effluents and biowaste is a threat to the durability and reliability of such structures. The effluents have complex and diverse compositions but they share some common characteristics: they initially contain mineral and more or less complex organic compounds in particulate or dissolved form, and microbial communities of animal or environmental origin. The complex chemical compounds in the effluents are degraded, through the action of the microorganisms, into simpler, oxidized molecules with lower molecular weights. The metabolites (end products of microbial metabolism) generated by the activity of microorganisms are mainly organic acids and ammonium, and gases $\left(\mathrm{CO}_{2}, \mathrm{CH}_{4}, \mathrm{H}_{2} \mathrm{~S}\right.$, among others). Some metabolites are aggressive for the cementitious material, as may be the microbial populations themselves, which can have a specific activating effect in the degradation [1-3]. Mechanical actions (passage of machinery in the plants, high-pressure cleaning, mechanical scraping, etc.) can add to the physicochemical alteration phenomena. This results in a loss of alkalinity, progressive erosion of cover concrete, decreased mechanical strength, and a loss of impermeability of the concrete to liquids and gases, or even in the ruin of the structure following corrosion of the reinforcements [4-10]. The consequences of these deteriorations in concrete structures are first of an economic nature for the operators (cost of repairing the structures and stopping the production tools during the works, reduced yield of the biogas production process due to leaks, etc.) but are also environmental (leakage of polluting effluents to the environment). Moreover, the current standard texts aiming at classifying aggressive environments for concrete [11,12] are incomplete and do not adequately describe the potential risks to concrete structures in agricultural and agro-industrial environments [13]. Developing durable concretes in agricultural and agro-industrial environments - which is an essential step in the successful development of fast growing sectors such as anaerobic digestion - requires a clear understanding of the mechanisms of concrete alteration in these aggressive, multi-component media that vary in both time and space.

This review aims to address the issues mentioned above. The characteristics of the main agricultural and agroindustrial wastes, including biowaste recovered by anaerobic digestion, are first detailed in terms of compounds that are potentially aggressive for cementitious materials. Then, current knowledge on mechanisms of concrete biodeterioration in agricultural and agro-industrial

* Corresponding author: Alexandra Bertron, E-mail: bertron@insa-toulouse.fr 
environments is exposed. The presentation is based on the results of laboratory tests (using phenomenological approaches intended to decouple the phenomena) and on tests conducted in complex real environments. The article also highlights the needs in terms of research and evolution of technical prescriptions over the coming years.

\section{Agricultural and agro-industrial effluents and biowaste}

In their initial state, agricultural effluents, such as manure, molasses, silage juices, whey or biowaste recovered in biogas plants, contain, among other compounds, more or less complex organic matter and microorganisms (bacteria, archaea, yeasts, fungi, etc.). The activity of these microorganisms degrades organic matter in the absence of oxygen. The main products of microbial anaerobic metabolism are organic acids with more or less long chains (acetic, lactic, citric, succinic, oxalic, tartaric, etc. acids), ammonium, and gases $\left(\mathrm{CO}_{2}, \mathrm{CH}_{4}, \mathrm{NH}_{3}, \mathrm{H}_{2}, \mathrm{H}_{2} \mathrm{~S}\right.$ etc.). Various sulfur, chloride, magnesium, or phosphorus salts are also found.

\subsection{Physicochemical characteristics of effluents}

The microbiological and chemical composition of the effluents is complex and changes over time depending on their nature, their storage conditions (mixing, aeration level, temperature, etc.), and various other parameters, such as the dilution ratio, the depth in the effluent, the animal feed in the case of livestock effluents, etc. [2]. In particular, the concentration of acids is variable and can reach several hundred millimoles per litre. The $\mathrm{pH}$ of most of these effluents is between 4 and $8[2,14,15]$. The compositions of liquid manure, silage juice and whey, and the biogas environment are presented below because they correspond to frequent environments for concrete. Readers interested in additional information about these media are invited to refer to the review by Bertron and Duchesne [2]. Effluents from the sugar (molasses) or alcoholic fermentation (vinasse) industries are not presented, but fairly detailed information can be found in [2].

\subsubsection{Liquid manure}

Manure is the essentially liquid mixture of faeces and urine of farm animals. It is usually stored in gas- and/or watertight containment structures, often made of concrete, to prevent leakage to the environment. During storage, it undergoes aerobic and anaerobic biological transformations. Liquid manure contains inorganic and organic compounds, including volatile fatty acids (or VFA, i.e. carboxylic acids with fewer than 6 carbon atoms): mainly acetic and propionic, but also butyric, and valeric acids, with a total concentration that may exceed $10 \mathrm{~g} / \mathrm{L}$. Due to the presence of the acid-base pair $\mathrm{NH}_{3} / \mathrm{NH}_{4}^{+}$[16], the $\mathrm{pH}$ of manure is generally between 6 and 8 [2]. In storage tanks, $\mathrm{CO}_{2}$ is produced in aerobic zones due to the biological oxidation of biodegradable carbon $[17,18]$.

\subsubsection{Silage juices and whey}

Silage juices and whey are presented in the same section because they have similar compositional characteristics in terms of aggressiveness towards the cement matrix.

\section{- $\quad$ Silage juices}

During silage, soluble sugars in green food are mainly converted to lactic acid (predominant acid, at concentrations of 5 to $40 \mathrm{~g} / \mathrm{L}$ ) and also to volatile fatty acids (mainly acetic acid), in anaerobic conditions and under the action of fermentative bacteria. The reactions are accompanied by acidification causing the $\mathrm{pH}$ to drop below 4 (usually 3.5 to 4). The reducing environment limits undesirable fermentation (such as the development of butyric flora) and ensures the conservation of the silage. Silage effluent can have very diverse compositions. The main determining factors are the nature of the silage (corn, grass, sugar cane, etc.), the silage mode (in balls, clamp, round or stack silos), the air content (airtightness is a very important factor for silage quality), the moisture content, the temperature, leaching due to rain, and the silage time. Examples of silage juice compositions are given in [2].

\section{- Whey}

Whey is the liquid phase separated from the solid phase (curd) during cheese making. It contains proteins, lactose, fats and minerals and also a large population of microorganisms. Because of its high lactose content, this effluent is rapidly subject to acid fermentation favouring the production of lactic, acetic and butyric acids and gas (especially $\mathrm{CO}_{2}$ ). Some whey may also contain citric acid. The $\mathrm{pH}$ can quickly reach values close to 3 or even 2 . The acidification process is accelerated with increasing temperature. Whey composition depends mainly on cheese processing techniques. Examples of whey compositions are given in [2].

\subsubsection{Biowaste in anaerobic digestion or biogas production}

Anaerobic digestion is a biological degradation process of agricultural or agro-food biowaste under anaerobic conditions, producing biogas that is energy-efficient in terms of electricity and/or heat (cogeneration). The biological process, called anaerobic digestion, involves four stages of successive organic matter degradation reactions: hydrolysis, acidogenesis, acetogenesis, and methanogenesis $[19,20]$. Optimum yields for these processes are obtained for temperatures close to $37^{\circ} \mathrm{C}$ or $55^{\circ} \mathrm{C}$ depending on the type of microbial populations involved (mesophilic or thermophilic, respectively). Methanogenesis is the ultimate step that results in the production of biogas, theoretically composed of $65 \%$ methane $\left(\mathrm{CH}_{4}\right)$ and $35 \%$ carbon dioxide $\left(\mathrm{CO}_{2}\right)$. The solid or liquid residue of the anaerobic digestion is the digestate. It is used as fertilizer/agricultural amendment. The economic and environmental benefits and interest of this process, used on an industrial scale, are numerous, making it an attractive and growing sector in Europe. During anaerobic digestion biowaste contains mainly acetic and propionic acids, and butyric acid in small quantities. The acid concentrations vary greatly depending on the effluent nature and the stage of anaerobic reactions (see, for 
example, [10]). The $\mathrm{pH}$ of biowaste is maintained between 7 and 8 during an anaerobic digestion cycle, which corresponds to the very specific $\mathrm{pH}$ conditions required by methanogenic microorganisms [20]. Sometimes a short period of $\mathrm{pH}$ drop can be observed at the start of the anaerobic digestion cycle during the acidogenesis phase. Ammonia is formed during the anaerobic digestion process. Given the $\mathrm{pH}$ conditions (7-8), and the pKa of the $\mathrm{NH}_{4}{ }^{+} / \mathrm{NH}_{3}$ acid-base pair (9.25), ammonia is present mainly in the ammonium ion form. Note that ammonium concentrations measured by Voegel et al. [10], for example, (up to 40 $\mathrm{mmol} / \mathrm{L}$ ) in biowaste, were about seven times higher than the upper limit $(5.55 \mathrm{mmol} / \mathrm{L})$ of exposure class XA3 (very aggressive chemical environment) defined by EN 206, and lower than the concentration of inhibition of anaerobic digestion (about $80 \mathrm{mmol} / \mathrm{L}$ ) given by McCarty [20]. In addition, the concentration of dissolved $\mathrm{CO}_{2}$ potentially encountered in industrial digesters (between 2000 and 3000 $\mathrm{mg} / \mathrm{L},[20]$ ) corresponds to an exposure class XA3. Other compounds aggressive for concrete are also found in biowaste, such as magnesium, chloride, or phosphorus salts. Moreover, the gas phase is mainly composed of $\mathrm{CO}_{2}$ and $\mathrm{CH}_{4}$, but is also likely to contain significant levels of $\mathrm{H}_{2} \mathrm{~S}$, which is responsible for other types of concrete biodeterioration in the gas phase [21].

\subsection{Effluent compositions versus standards on classification of aggressive environments}

The normative documents classifying chemically aggressive environments for concrete, i.e. standard EN 206/CN [11], and the French information document FD P 18-011 [12] do not currently provide a comprehensive and relevant description of the potential risk that agricultural, agro-food and anaerobic digestion environments pose for cementitious materials. Organic acids are not considered at all in these texts, acidity-related aggressiveness being mainly indexed by $\mathrm{pH}$, which has been shown to be irrelevant for some organic acids $[1,14]$. Their specificity should therefore be considered. Neither do these texts mention the biological component as a potential aggressive agent, although this has been demonstrated in agricultural media as in other biological environments $[3,22,23]$. It should also be noted that the potential effect of temperature is not taken into account, even though the optimum temperature of anaerobic digestion processes, for example, is $37^{\circ} \mathrm{C}$ or $55^{\circ} \mathrm{C}$. However, increased temperature can (i) be a factor accelerating reaction kinetics between cementitious materials and aggressive microbial metabolites and/or (ii) change the stability of the cementitious phases.

More generally, agricultural and agro-industrial environments are multi-component, multi-phasic environments, the composition of which constantly evolves over time and space, during storage or processing. The characterization of their liquid and gas phase compositions must be the subject of further in-depth investigations in order to accurately evaluate the risk for the durability of structures.

\section{Cementitious material biodeterioration phenomena}

In order to progress in understanding the mechanisms of cementitious material alteration in contact with agricultural and agro-industrial effluents, an analytical approach is adopted here. It is based on two types of investigations: the first involves model or synthetic media, allowing the mechanisms of alteration by aggressive compounds to be identified when they are taken individually. The second type considers the combination of compounds to complete media.

\subsection{Decoupled analysis of deterioration by isolated aggressive compounds}

The main aggressive agents for cementitious materials in agricultural and agro-industrial environments are organic acids, ammonium, $\mathrm{CO}_{2}$, and various sulfur, chloride, and phosphorus (among other) salts. The microorganisms themselves may also have a specific effect. The mechanisms of their respective attacks on the cementitious matrix are explained or the relevant references of the literature are recalled below.

\subsubsection{Alteration mechanisms by organic acids}

A wide range of organic acids is found in agricultural and agro-industrial effluents (acetic acid and other volatile fatty acids, lactic, malic, oxalic, citric, and tartaric acids, etc.). These carboxylic acids are weak acids, i.e. they partially dissociate in water $[24,25]$ into hydronium ion and the acid anion. The hydronium ion causes the gradual dissolution of the hydrated and anhydrous compounds of the cement matrix, mainly releasing calcium ions. Depending on the chemical conditions and on their formation constants, salts and/or complexes resulting from the reaction between calcium and the anion of the acid may be formed [26]. The aggressiveness of organic acids for the cement matrix depends on three types of parameters: the chemical properties of the acids (pKa, polyacidity), the properties of the calcium salts (solubility, molar volume, affinity for the matrix, mesoscopic shape, etc.), and the physicochemical characteristics of the cement matrix (chemical and mineralogical composition, porosity) [2]. A classification of these parameters' influence is proposed in [1]. The first governing criterion is that of the solubility of calcium salts. For acids with soluble calcium salts (acetic acids and other volatile fatty acids, lactic acid), calcium salts do not form under immersion conditions and chemical attack results in a progressive dissolution of all hydrated and anhydrous phases of the cement matrix (depending on the $\mathrm{pH}$ and concentration of acids). Calcium, magnesium, sulfur and alkalis are leached, leaving a porous skeleton of Si-Al gel [2733] (Fig. 1). When calcium salts are not very soluble in water, their formation can protect the cement matrix either temporarily (e.g. tartaric acid) or durably (e.g. oxalic acid), or worsen the deterioration phenomena and increase the kinetics (e.g. citric and succinic acids) [2,14]. The preponderant parameter is the molar volume of calcium salts in relation to the porosity of the matrix [14]. The 
solubility of the salts, their affinity for the matrix or their mesoscopic shape also play a role but the influence of the latter has not been apprehended and quantified so far [1].

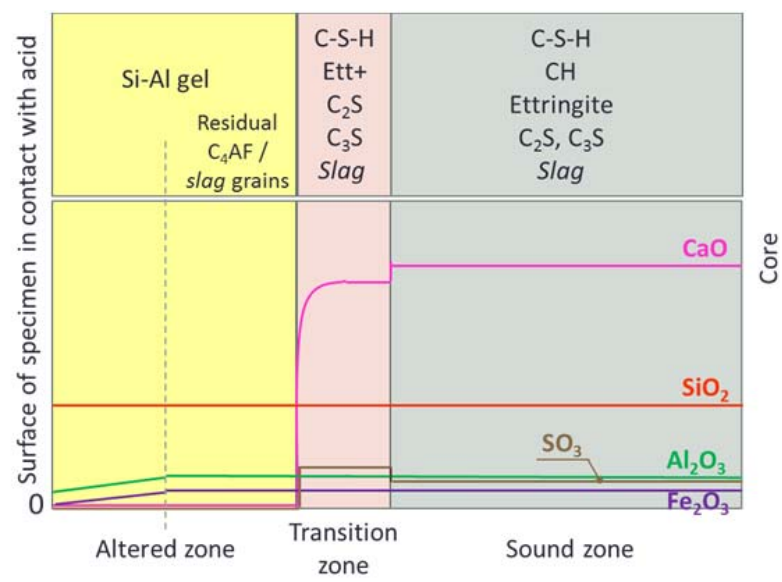

Figure 1. Typical mineralogical and chemical changes in CEM I / CEM III cement paste specimens $(\mathrm{W} / \mathrm{C}=0.27)$ exposed to organic acid with soluble salts (e.g. acetic acid and other volatile fatty acids), for $\mathrm{pH}$ between 4 and 6 and concentration of acids of $0.3 \mathrm{mM}$. This diagram synthetizes data from EPMA, XRD and NMR ${ }^{29} \mathrm{Si}$ and ${ }^{27} \mathrm{Al}$ analyses $[27,28,34]$. Ett+: secondary, non-harmful ettringite precipitated in transition zone. The thicknesses of the altered and transition zones are typically $2000 \mu \mathrm{m}$ and $200 \mu \mathrm{m}$, respectively.

\subsubsection{Other chemical compounds}

The individual action of $\mathrm{CO}_{2}$, ammonium or other compounds, such as magnesium or sulfate salts, in the effluents is described in the literature in non-specific studies of agricultural environments [35-39]. These aspects will not be detailed; the reader is invited to refer to these publications.

\subsubsection{Specific action of microorganisms}

Identifying the possible specific effect of microorganisms in alteration phenomena is important because it indicates whether or not it is necessary to set up biological rather than strictly chemical tests to characterize the performance of cementitious materials in such media. These investigations require the implementation of specific experimental devices intended to integrate the biological component in a relevant way (no standardized test exists so far). Such a device was developed in a study involving a model manure (using a common strain of bacteria present in many effluents: Escherichia coli) [3]. The device (the BMB test) was designed to enable the comparison of mineralogical and chemical changes and degradation depths in cementitious materials exposed to two types of media. The first was a complete medium ( $E$. coli and the products of its metabolism, i.e. organic acids and $\mathrm{CO}_{2}$, in particular, medium 1 ), and the second was obtained from the first medium but with its bacteria removed by a $0.2 \mu \mathrm{m}$ biomass filtration system (thus containing only the products of their metabolism, medium 2). Media 1 and 2 had very close average chemical compositions and a $\mathrm{pH}$ of about 8. A complementary experiment was also conducted with only the strictly acid component of the medium (acetic and lactic acids in adjusted concentrations, medium 3). Comparing the alteration patterns of cement paste exposed to the three media highlighted a significant effect related to the presence of a biofilm on the surface of the cementitious material: in four weeks of exposure, the degraded depths were twice as high in medium 1 (1.3 $\mathrm{mm}$ for a paste of CEM I) as in medium $2(0.65 \mathrm{~mm})$ and the intensity of alteration in terms of decalcification close to the surface was significantly higher in medium 1. The authors explain that the formation of a biofilm on the surface of the cement paste generated significantly more aggressive local conditions (in terms of concentrations of aggressive agents) than those developed in the surrounding environment. The alterations generated by medium 3 were less severe in all respects, presumably due to the absence of some aggressive compounds present in the complete medium (notably $\mathrm{CO}_{2}$ ). These results show that the biological component can generate a specific effect and that it is necessary to take the multi-component nature of the effluents into account.

\subsection{Alteration mechanisms in complete media}

A number of studies aimed at exploring the durability of concrete in agricultural and agro-industrial environments have been conducted in real-life settings. In coherence with section 1 of this paper, the three types of environment considered, classified by families of chemical compositions are: liquid manure, silage juice and whey, and biogas environments. The understanding of alteration phenomena relies notably on studies carried out with synthetic media (media reconstituted from chemical components) and/or model media (simplified media) as presented in the previous section.

\subsubsection{Liquid manure}

Some studies have investigated the alteration mechanisms of cementitious materials by real manure $[5,8]$. The severity of the attack is generally qualified as moderate. This depends on the manure composition, which may be more or less diluted by wash water or precipitation. The $\mathrm{pH}$ of manure is generally between 6 and 8 . The attack results in a moderate decalcification, the matrix being intensely carbonated on the surface [5], and the alteration kinetics are low compared to other agricultural environments (depth less than $80 \mu \mathrm{m}$ after one month of exposure as reported in [5]) (Fig. 2). But, in the long term deterioration may significantly affect the cover concrete, especially for medium quality concretes, and lead to corrosion of the reinforcement.

\subsubsection{Silage juices and whey}

Experimental campaigns carried out on concretes exposed to silage juices or whey can be found in the literature. Most of them mainly focus on the evaluation of different materials' performance without considering alteration mechanisms [40-42]. Experiments exploring biodeterioration mechanisms in such effluents, the average $\mathrm{pH}$ of which is about 3.5-4, are fewer [5,21]. They show a predominant role of the acids (acetic, lactic and citric acids) and little or no carbonation pattern. The cement matrix shows intense decalcification and dissolution of aluminium and iron in the outer zone (Fig. 2), a sign that the surface $\mathrm{pH}$ is likely to have reached values significantly lower than 4 , probably due to the formation of a microbial biofilm on the 
surface. This biofilm generates more aggressive local conditions than the average environment analyses suggest.

a)

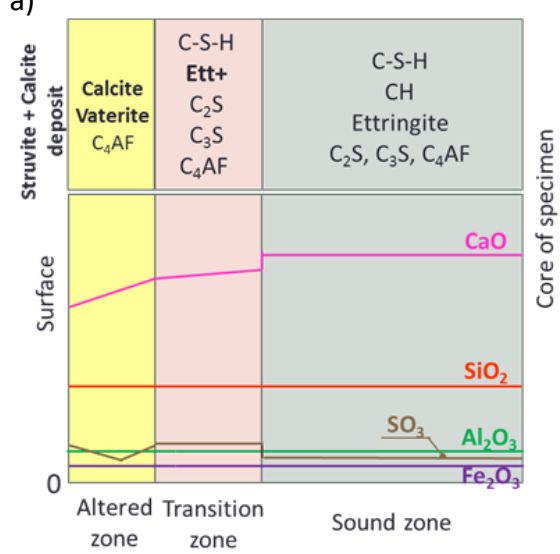

b)

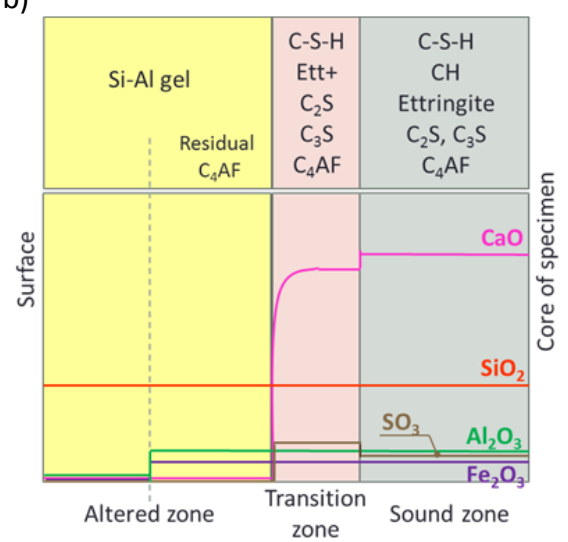

Figure 2. Typical mineralogical and chemical changes in CEM I cement paste specimen ( $\mathrm{W} / \mathrm{C}=0.27)$ exposed to a) liquid manure and b) whey (see main chemical conditions in text). This diagram synthetizes data from EPMA, XRD and SEM-EDS analyses [5], [27]. Ett+: secondary non-harmful ettringite precipitated in the transition zone. In the conditions of the experiments, the thickness of the altered and transition zones were $90 \mu \mathrm{m}$ and $120 \mu \mathrm{m}$, respectively, for a) and $2000 \mu \mathrm{m}$ and $200 \mu \mathrm{m}$, respectively, for b) after 4 weeks of exposure [9].

\subsubsection{Biogas systems}

Recent studies focus on the issue of concrete biodeterioration in anaerobic digestion structures $[9,10,15$, $21,43]$. The current growth of the biogas sector, where structures are often made of concrete, makes it necessary to investigate alteration mechanisms and performance of concrete in these environments [9]. The core of the industrial process of anaerobic digestion is the digester, in which the organic fraction of a solid or liquid biowaste is transformed, under the action of microorganisms with anaerobic metabolisms, into biogas and digestate (solid and/or liquid digestion residue). In a running digester, two distinct zones are identified as risk zones for concrete material: the liquid part containing dissolved aggressive metabolites (volatile fatty acids, ammonium, $\mathrm{CO}_{2}, \mathrm{Mg}$, $\mathrm{P}$ and $S$ salts, in particular), and the gas phase with high concentrations of $\mathrm{CO}_{2}$ and $\mathrm{H}_{2} \mathrm{~S}$.

\section{- Deterioration in liquid phase}

The work of Voegel et al. [10] explored biodeterioration phenomena in the submerged part of the digester using a typical food biowaste. Normal operating conditions and accident conditions leading to the disruption of the anaerobic digestion process have been studied $[9,10,43]$. The usual conditions correspond to normal operation of anaerobic digestion. The metabolites produced are, mainly, organic acids (which disappear at the end of the cycle), ammonium, $\mathrm{CO}_{2}$ and $\mathrm{CH}_{4}$. The $\mathrm{pH}$ is between 7 and 8 . Voegel et al. showed that alteration mechanisms corresponded to a combination of leaching (related to the action of organic acids and ammonium), carbonation, and a significant effect of surface biofilm formation (almost complete decalcification suggesting local production of aggressive metabolites at high concentrations). Amorphous calcium phosphate presumably precipitated in the outer part of the altered zone (phosphate contained in the biowaste) (Fig. 3).

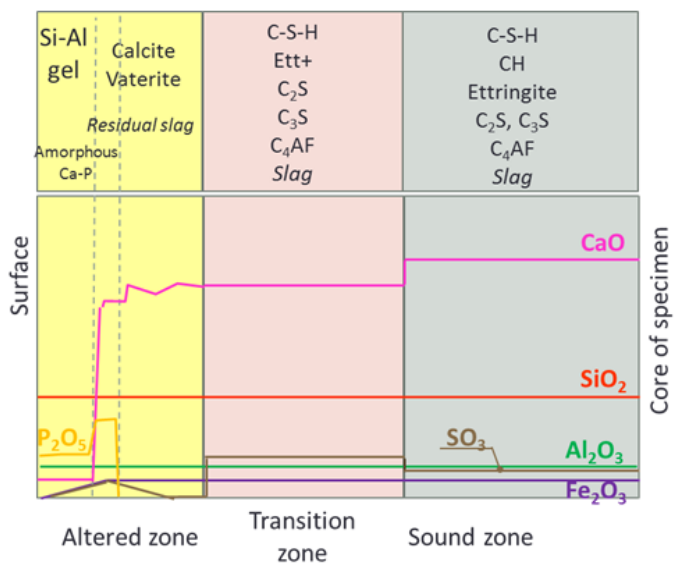

Figure 3. Typical mineralogical and chemical changes in CEM I and CEM III cement paste specimens $(W / C=0.4)$ exposed to the liquid phase of a lab digester (see chemical conditions in text). This diagram synthetizes data from EPMA, XRD and SEM-EDS analyses. Ett+: secondary non-harmful ettringite precipitated in transition zone. For CEM I paste, the thickness of the altered zone and of the transition zone were $300 \mu \mathrm{m}$ and $400 \mu \mathrm{m}$, respectively, after 5 weeks of exposure [9].

These results obtained in laboratory experiments were confirmed, in terms of mechanisms and kinetics of alteration, by in-situ immersion experiments of cement samples in the digester of a pre-industrial biogas plant fermenting real agricultural waste (bovine manure) [9]. In addition, Koenig and Dehn's experiments [21] in the liquid phase of a digester also revealed intense carbonation of the cement matrix.

\section{- Deterioration in gas phase}

Keonig and Dehn [21] exposed concrete cores in the gas phase of an anaerobic digester previously desulfurized by atmospheric oxygenation to reduce the $\mathrm{H}_{2} \mathrm{~S}$ concentration to less than $500 \mathrm{mg} / \mathrm{m}^{3}$ (about $360 \mathrm{ppm}$ ). After 18 months of experiment, the samples showed signs of intense alteration related to the reactions with $\mathrm{H}_{2} \mathrm{~S}$ and $\mathrm{CO}_{2}$ in the gas phase: precipitates of sulfur products (elemental sulfur, crystallized or not) and gypsum and other polymorphic crystalline 
phases of calcium carbonates were identified. Microorganism identification at the surface of the specimens highlighted the presence of heterotrophic bacteria capable of oxidizing organic substrates and a large population of sulfur-oxidizing bacteria. The presence of the latter was probably made possible by the oxygenation process used to reduce the $\mathrm{H}_{2} \mathrm{~S}$ concentration in the gas phase. The phenomena of biodeterioration under strictly anaerobic conditions in the gas phase (i.e. without voluntary oxygenation) must be investigated.

\section{Conclusion}

The chemical (organic acids, ammonium and $\mathrm{CO}_{2}$ in particular), and biological (specific effect of biofilm on the surface of materials) components of agricultural and agroindustrial environments are responsible for severe attacks on cementitious materials. Mechanisms of concrete deterioration have been studied, more or less comprehensively, in the literature by considering the individual and combined action of different aggressive agents, in model and real environments, and have enabled understanding to progress. Regarding the action of organic acids on materials, various aspects have yet to be clarified, notably the influence of certain properties of acid salts (e.g. the salt's affinity for the matrix, its mesoscopic shape and its mechanical properties). Knowledge of the combined action of aggressive metabolites (organic acids, ammonium and $\mathrm{CO}_{2}$, in particular) also needs to be refined to tend towards a predictive approach of the aggressiveness of the effluents. It has been clearly demonstrated that the $\mathrm{pH}$ should not be considered as the sole indicator of the aggressiveness of acidic media: the acid composition must also be evaluated (nature of acids and concentrations). In this perspective, standards defining the classification of chemical environments aggressive to concrete should be improved. Regarding the specific effect of the biological component, there is currently no standard test method for qualifying concrete in microorganism-bearing environments. This gap must be filled in the coming years, particularly on the basis of test methods proposed in the literature. In addition, the design requirements for concrete destined for use in these environments must be adapted to better consider the specificities of biodeterioration. Finally, in the particular case of anaerobic digestion, the studies recorded in the literature show that the anaerobic digestion medium is very aggressive for concrete, notably because of high concentrations of some metabolites. Further investigation should focus on (i) the complete characterization of biowaste in terms of concentrations of aggressive agents in the different configurations that may be encountered (variability of waste, exacerbated metabolic pathways), (ii) the evaluation of concrete alteration mechanisms in these different situations and (iii) the development of high performance cementitious materials. This is the purpose of the French ANR BIBENdOM project (2016-2020) in which the authors of the present paper are involved.

\section{References}

[1] A. Bertron, Understanding interactions between cementitious materials and microorganisms: a key to sustainable and safe concrete structures in various contexts. Mater Struct (2014) 47: 1787-1806. https://doi.org/10.1617/s11527-014-0433-1

[2] A. Bertron, J. Duchesne, Attack of Cementitious Materials by Organic Acids in Agricultural and Agrofood Effluents. In: M. Alexander, A. Bertron, and N. D. Belie (Eds), Performance of Cement-Based Materials in Aggressive Aqueous Environments, RILEM State of the Art Report 10, Springer Netherlands, 2013, 131173. https://doi.org/10.1007/978-94-007-5413-3 6

[3] C. Magniont et al., A new test method to assess the bacterial deterioration of cementitious materials. Cem Concr Res (2011) 41: 429-438. https://doi.org/10.1016/j.cemconres.2011.01.014

[4] J. Bensted, Effect of silage upon hardened cement and concrete. II Cem (1993) 1: 3-10.

[5] A. Bertron, M. Coutand, X. Cameleyre, G. Escadeillas, and J. Duchesne, Attaques chimique et biologique des effluents agricoles et agroalimentaires sur les matériaux cimentaires. Matér Tech (2005) 93:111-121

[6] N. De Belie, A Survey on concrete floors in pig houses and their degradation. J Agric Eng Res (1997) 66: 151-156. https://doi.org/10.1006/jaer.1996.0137

[7] J. Johnson, Détérioration des silos-tours en béton. Ministère de I'Agriculture, de l'Alimentation et des Affaires Rurales Ontario, Fiche Technique 08-058, 2008.

[8] E. Sanchez Espinosa, A. Moragues Terrades, J. Massana Guitart, R. Antón Fuentes, J. Lopez Dominguez, and M. A. Garcimartin Molina, Strength and porosity evolution of two cement mortar submerged in pig slurry. 2008.

[9] C. Voegel, Impact Blochimique des effluents agricoles et agroindustriels sur les structures/ouvrages en BEtOn dans la filière de valorisation par Méthanisation (ou codigestion anaérobie). PhD Thesis, Toulouse, INPT, 2017.

[10] C. Voegel, A. Bertron, and B. Erable, Mechanisms of cementitious material deterioration in biogas digester. Sci Total Environ (2016) 571: 892-901. https://doi.org/10.1016/j.scitotenv.2016.07.072

[11] AFNOR, NF EN 206/CN - Béton - Spécification, performance, production et conformité - Complément national à la norme NF EN 206. 2014.

[12] AFNOR, FD P18-011 - Béton - Définifion et classification des environnements chimiquement agressifs - Recommandations pour la formulation des bétons. 2016.

[13] A. Bertron, C. Voegel, B. Erable, and G. Escadeillas, Durabilité des bétons dans les structures des secteurs agricoles, agroalimentaires et la méthanisation. Ann Bâtim Trav Publics (2015) 67: 30-38.

[14] S. Larreur-Cayol, A. Bertron, and G. Escadeillas, Degradation of cement-based materials by various organic acids in agro-industrial waste-waters. Cem Concr Res (2011) 41: 882-892. https://doi.org/10.1016/i.cemconres.2011.04.007

[15] C. Voegel, A. Bertron, and B. Erable, Biological and chemical attack of cement-based materials in on-farm biogas plants. in Proceedings of the International Conference on Durability of Building Materials and Components, Sao Paulo, 2014.

[16] S. G. Sommer and N. Hutchings, Techniques and strategies for the reduction of ammonia emission from agriculture. Water Air Soil Pollut (1995) 85: 237-248. https://doi.org/10.1007/BF00483704

[17] R. H. Grant, M. T. Boehm, and B. W. Bogan, Methane and carbon dioxide emissions from manure storage facilities at two free-stall dairies. Agric For Meteorol (2015) 213: 102-113.

[18] S. G. Sommer, Ammonia volatilization from farm tanks containing anaerobically digested animal slurry. Atmos Environ (1997) 31: 863-868. https://doi.org/10.1016/S1352-2310(96)00250-6

[19] Cole Smith and J. R. Frank, Methane from Biomass: A Systems Approach, Springer. 1988.

[20] P. L. McCarty, Anaerobic waste treatment fundamentals - Part I to IV. Public Works (1964) 95: 9-12.

[21] A. Koenig and F. Dehn, Biogenic acid attack on concretes in biogas plants. Biosyst Eng (2016) 147: 226-237. https://doi.org/10.1016/j.biosystemseng.2016.03.007

[22] M. G. Alexander and C. Fourie, Performance of sewer pipe concrete mixtures with portland and calcium aluminate cements subject to mineral and biogenic acid attack. Mater Struct (2011) 44: 313-330. https://doi.org/10.1617/s11527-010-9629-1 
[23] A. Leemann, B. Lothenbach, and C. Hoffmann, Biologically induced concrete deterioration in a wastewater treatment plant assessed by combining microstructural analysis with thermodynamic modeling. Cem Concr Res (2010) 40: 1157-1164. https://doi.org/10.1016/j.cemconres.2010.03.007

[24] A. Bertron, Methods for testing cementitious materials exposed to organic acids, in performance of cement-based materials in aggressive aqueous environments, M. Alexander, A. Bertron, and N. D. Belie, Eds. Springer Netherlands (2013): 355-387. https://doi.org/10.1007/978-94-007-5413-3 15

[25] A. Koenig and F. Dehn, Main considerations for the determination and evaluation of the acid resistance of cementitious materials. Mater Struct (2016) 49: 1693-1703. https://doi.org/10.1617/s11527-015-0605-7

[26] L. De Windt, A. Bertron, S. Larreur-Cayol, and G. Escadeillas, Interactions between hydrated cement paste and organic acids: Thermodynamic data and speciation modeling. Cem Concr Res (2015) 69: 25-36. https://doi.org/10.1016/i.cemconres.2014.12.001

[27] A. Bertron, Durabilité des matériaux cimentaires soumis aux acides organiques, Cas particulier des effluents d'élevage. PhD Thesis, INSA Toulouse, 2004.

[28] A. Bertron, J. Duchesne, and G. Escadeillas, Accelerated tests of hardened cement pastes alteration by organic acids: analysis of the pH effect. Cem Concr Res (2005) 35: 155-166. https://doi.org/10.1016/j.cemconres.2004.09.009

[29] T. Dyer, Influence of cement type on resistance to attack from two carboxylic acids. Cem Concr Compos (2017) 83: 20-35. https://doi.org/10.1016/j.cemconcomp.2017.07.004

[30] A. Koenig, A. Herrmann, S. Overmann, and F. Dehn, Resistance of alkali-activated binders to organic acid attack: Assessment of evaluation criteria and damage mechanisms. Constr Build Mater (2017) 151: 405-413. https://doi.org/10.1016/j.conbuildmat.2017.06.117

[31] V. Pavlík, Corrosion of hardened cement paste by acetic and nitric acids part II: Formation and chemical composition of the corrosion products layer. Cem Concr Res (1994) 24: 1495-1508. https://doi.org/10.1016/0008-8846(94)90164-3

[32] K. P. Ramaswamy, A. Bertron, and M. Santhanam, Additional insights on the influencing factors and mechanism of degradation due to acid attack: special case of acids forming soluble salts. presented at the International Conference on Advances in Construction Materials and Systems, Madras, 2017.

[33] K. P. Ramaswamy and M. Santhanam, A study of deterioration of cement paste due to acid attack using X-ray computed microtomography. Adv Cem Res (2017): 1-16. https://doi.org/10.1680/jadcr.17.00032

[34] A. Bertron, J. Duchesne, and G. Escadeillas, Degradation of cement pastes by organic acids. Mater Struct (2007) 40: 341-354. https://doi.org/10.1617/s11527-006-9110-3

[35] C. Carde and R. François, Effect of the leaching of calcium hydroxide from cement paste on mechanical and physical properties. Cem Concr Res (1997) 27: 539-550. https://doi.org/10.1016/S0008-8846(97)00042-2

[36] G. Escadeillas, Ammonium nitrate attack on cementitious materials. n: M. Alexander, A. Bertron, and N. D. Belie (Eds), Performance of Cement-Based Materials in Aggressive Aqueous Environments, RILEM State of the Art Report 10, Springer Netherlands, (2013): 113-130. https://doi.org/10.1007/978-94-007-5413-3_5

[37] A. Morandeau, M. Thiéry, and P. Dangla, Investigation of the carbonation mechanism of $\mathrm{CH}$ and $\mathrm{C}-\mathrm{S}-\mathrm{H}$ in terms of kinetics, microstructure changes and moisture properties. Cem Concr Res (2014) 56: 153-170.

[38] M. Thiery, V. Baroghel-Bouny, A. Morandeau, and P. Dangla, Impact of carbonation on the microstructure and transfer properties of cement-based materials (2012).

[39] M. Alexander, A. Bertron, and N. De Belie, Eds., Performance of cement-based materials in aggressive aqueous environments, Springer., vol. RILEM TC 211-PAE. Berlin: Springer Netherlands, 2013. https://doi.org/10.1007/978-94-007-5413-3

[40] C. O'Donnell, V. A. Dodd, P. O'Kiely, and M. Richardson, A study of the effects of silage effluent on concrete: part 1 , significance of concrete characteristics. J Agric Eng Res (1995) 60: 83-92. https://doi.org/10.1006/jaer.1995.1002

[41] C. O'Donnell, P. O'Kiely, V. A. Dodd, and M. Richardson, A study of the effects of silage effluent on concrete: part 2, significance of environmental factors. J Agric Eng Res (1995) 60: 93-97. https://doi.org/10.1006/jaer.1995.1003

[42] M. Richardson, V. A. Dodd, J. J. Lenehan, S. Conaty, and P. O'Kiely, The influence of cement content and water/cement ratio on the durability of portland cement concretes exposed to silage effluent. J Agric Eng Res (1999) 72: 137-143. https://doi.org/10.1006/jaer.1998.0355

[43] C. Voegel, A. Bertron, and B. Erable, Biodeterioration of cementitious materials in biogas digester. Matér Tech (2015) 103. https://doi.org/10.1051/mattech/2015023 